\title{
Clinicopathological and immunohistochemical study of extrapleural and pleural solitary fibrous tumors: A special emphasis on the comparison between ordinary tumors and their malignant variant
}

\author{
MARI NAKAMORI，YOSHINAO ODA，SHUICHI KURIHARA and MASAZUMI TSUNEYOSHI \\ Department of Anatomic Pathology, Graduate School of Medical Sciences, Kyushu University, Fukuoka, Japan
}

Received July 1, 2008; Accepted September 8, 2008

DOI: $10.3892 / \mathrm{mmr} 00000031$

\begin{abstract}
Solitary fibrous tumors (SFTs) are rare spindle cell tumors that usually arise in the pleura, although they also occur in extrapleural sites. SFTs usually have a favorable clinical course; however, a small number of metastasizing cases have been reported. We evaluated the detailed clinicopathological findings of 20 extrapleural and 16 pleural SFTs. Among them, 6 cases of the histologically malignant variant (4 extrapleural and 2 pleural tumors) were identified. According to the followup data, none of the cases, including the 6 malignant tumors, developed metastases in this series. There were no significant differences in the histologic findings between the extrapleural and pleural SFTs. Tumor necrosis was frequently associated with the malignant variant. Immunohistochemically, malignant SFTs revealed more frequent p53 expression (4/6) compared with ordinary SFTs (2/30) $(\mathrm{P}=0.0027)$. The MIB-1 labeling index (LI) was significantly higher in malignant SFTs (mean 13.48) than in ordinary SFTs (mean 7.27) $(\mathrm{P}=0.0023)$. Our results indicate that tumor necrosis, p53 expression and a high MIB-1 LI are additional parameters of the malignant variant of SFTs, although they do not necessarily have predictive value for biological behavior. Further studies are required to find reliable molecular biomarkers for predicting the clinical outcome of patients with this unique tumor.
\end{abstract}

\section{Introduction}

Solitary fibrous tumors (SFTs) are rare mesenchymal neoplasms that occur preferentially in the pleura (1), but have also been reported in other serosal membranes and organs (2). Although the histological criteria of malignant pleural SFTs were initially proposed by England et al (3), they do

Correspondence to: Dr Yoshinao Oda, Department of Anatomic Pathology, Graduate School of Medical Sciences, Kyushu University, 3-1-1 Maidashi, Higashi-ku, Fukuoka 812-8582, Japan

E-mail: oda@surgpath.med.kyushu-u.ac.jp

Key words: solitary fibrous tumor, p53, MIB-1 labeling index not necessarily reflect the biological behavior of the tumor. Moreover, this histological definition of malignant phenotype has also been adopted in extrapleural SFTs and compared with clinical outcome by several authors (4-6). Since VallatDecouvelaere et al (7) demonstrated metastasizing malignant extrapleural SFTs, extrapleural SFTs have been categorized as intermediate rarely metastasizing tumors in the World Health Organization (WHO) classification (2). A high MIB-1 labeling index (LI) has been reported to be associated with the malignant phenotype in SFT $(8,9)$. In this study, we compared detailed histological findings, such as myxoid change, storiform pattern, necrosis and hemorrhage, between ordinary and malignant SFTs, along with pleural and extrapleural tumors. Furthermore, p53 expression and proliferative activities as measured by the MIB-1 LI were assessed in ordinary and malignant SFTs.

\section{Materials and methods}

Cases. Thirty-six cases (20 extrapleural and 16 pleural) of SFT that occurred between 1974 and 2005 were retrieved from the soft tissue tumor files at the Department of Anatomic Pathology, Kyushu University. The diagnosis of these cases was based on light-microscopic examination with hematoxylineosin (H\&E) staining according to the recent WHO classification $(1,2)$.

Further detailed histopathological features were investigated using H\&E-stained microscopic specimens. Malignancy was defined according to the established criteria of England et al (3). Tumors were considered histologically malignant when one or more of the following histological features were present: high cellularity, $>4$ mitotic figures per 10 high power fields (HPFs), or pleomorphism. Moreover, we assessed the presence of myxoid change, storiform pattern, necrosis and hemorrhage. Clinical details and follow-up information were obtained from hospital records and from the referring pathologists or physicians, respectively.

Immunohistochemical staining. Representative formalin-fixed paraffin-embedded tissue blocks for immunohistochemistry were available in all 36 cases. Immunohistochemical study was performed using monoclonal antibodies against CD34 (clone: QBEnd/10, 1:50) (Novocastra Laboratories, Newcastle, 

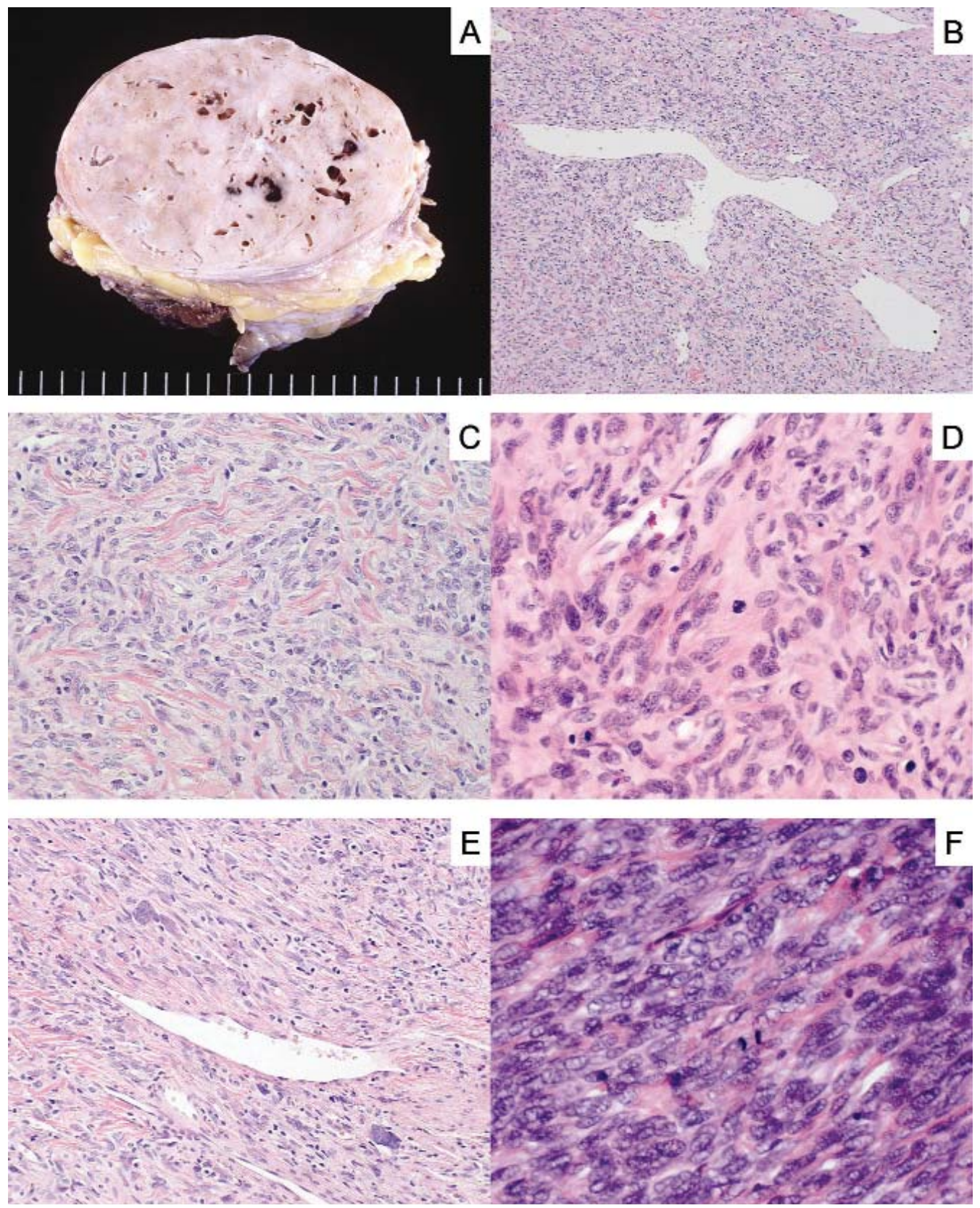

Figure 1. (A) Grossly, the cut surface of the tumor shows a well-circumscribed mass with a tan-to-gray color. (B) Branching hemangiopericytomatous vessels are prominent throughout the tumor. (C) Spindle-shaped tumor cells are arranged in patternless architecture with intermingling dense collagen fibers. (A-C) Malignant extrapleural SFT; Case 17. (D) Mitotic figures are frequently seen in the proliferating tumor cells (malignant extrapleural SFT; Case 20). (E) Focally, tumor giant cells with unusual nuclei are evident (malignant extrapleural SFT; Case 17). (F) Short spindle cells disclose cellular proliferation with frequent mitotic figures (malignant pleural SFT; Case 16).

UK), bcl-2 (clone: 124, 1:100) (Dako, Grostrup, Denmark), $\alpha$-smooth muscle actin (clone: 1A4, 1:5000) (Sigma BioSciences, St. Louis, MO), pan-cytokeratin (clone: AE1/AE3, 1:400) (Dako), p53 (clone: Pab 1801, 1:100) (Oncogene Research Products, Cambridge, CA) and Ki-67 (MIB-1, 1:100) (Dako).

Histological sections $(4 \mu)$ of $10 \%$ formalin-fixed paraffinembedded materials were cut, mounted on glass slides coated with 3-aminopropyltriethoxysilane and air dried overnight at room temperature. The sections were deparaffinized in xylene and dehydrated in ethanol. After dehydration, endogenous peroxidase was blocked by methanol containing $0.3 \% \mathrm{H}_{2} \mathrm{O}_{2}$ for $30 \mathrm{~min}$. The sections were incubated with primary antibody at $4^{\circ} \mathrm{C}$ overnight, followed by staining with an avidin biotin peroxidase kit (Nichirei, Tokyo, Japan). Lastly, the sections were reacted with a 3,3'-diaminobenzidine peroxytrichloride substrate solution, counterstained with methyl green or hematoxylin, and mounted.

As for the antibodies for Ki-67 and p53, specimens were pre-treated by microwave irradiation to retrieve antigen. The results of the immunostains were semiquantitated according to the following scale: -, absence of immunoreactive tumor cells; ,$+ 0-25 \%$ of positive tumor cells;,$++ 25-75 \%$ of positive tumor cells;,$+++>75 \%$ of positive tumor cells. The MIB-1 LI was determined by counting at least 500 tumor cells.

Statistical analysis. The difference in histological findings and immunohistochemical expression between pleural and 
Table I. Clinical and pathologic data of 20 patients with extrapleural solitary fibrous tumor.

\begin{tabular}{|c|c|c|c|c|c|c|c|c|c|c|}
\hline $\begin{array}{l}\text { Case } \\
\text { no. }\end{array}$ & $\begin{array}{l}\text { Age (years)/ } \\
\text { gender }\end{array}$ & Location & $\begin{array}{l}\text { Size } \\
(\mathrm{cm})\end{array}$ & $\mathrm{MC}$ & $\mathrm{SP}$ & $\mathrm{NC}$ & $\mathrm{HM}$ & $\begin{array}{l}\text { Mitosis/ } \\
10 \mathrm{HPF}\end{array}$ & $\mathrm{P}$ & Follow-up \\
\hline 1 & $63 / \mathrm{M}$ & Thigh & 27 & + & + & - & - & 0 & - & 50 mo NED \\
\hline 2 & $48 / \mathrm{M}$ & Oral cavity & 2 & - & + & - & - & 0 & - & 43 mo NED \\
\hline 3 & $45 / \mathrm{F}$ & Abdominal wall & 3 & - & + & - & - & 0 & - & 38 mo NED \\
\hline 4 & $48 / \mathrm{F}$ & Pelvic cavity & 3 & - & - & - & - & 0 & - & 2 mo NED \\
\hline 5 & $56 / \mathrm{F}$ & Pelvic cavity & 15 & + & - & - & - & 0 & - & NA \\
\hline 6 & $72 / \mathrm{M}$ & Abdominal wall & 6 & + & + & - & - & 0 & - & 30 mo NED \\
\hline 7 & $47 / \mathrm{F}$ & Retroperitoneum & 4 & - & - & - & + & 1 & - & 13 mo NED \\
\hline 8 & $71 / \mathrm{M}$ & Groin & 6 & - & - & - & - & 1 & - & 11 mo NED \\
\hline 9 & $47 / \mathrm{F}$ & Abdominal cavity & NA & - & - & - & - & 0 & - & NA \\
\hline 10 & $56 / \mathrm{F}$ & Orbit & 6.4 & - & - & - & - & 0 & - & NA \\
\hline 11 & $60 / \mathrm{M}$ & Deltoid region & NA & - & + & - & - & 1 & - & 62 mo NED \\
\hline 12 & $25 / \mathrm{F}$ & Orbit & 1 & - & - & - & - & 0 & - & 45 mo NED \\
\hline 13 & $68 / \mathrm{M}$ & Thigh & NA & + & - & - & - & 0 & - & NA \\
\hline 14 & $55 / \mathrm{F}$ & Retroperitoneum & 15 & - & + & - & - & 0 & - & NA \\
\hline 15 & $41 / \mathrm{M}$ & Pelvic cavity & 8 & - & - & - & - & 0 & - & NA \\
\hline 16 & $51 / \mathrm{M}$ & Abdominal wall & 7 & - & - & - & - & 0 & - & NA \\
\hline \multicolumn{11}{|c|}{ Malignant } \\
\hline 17 & $59 / \mathrm{M}$ & Buttock & 7.5 & - & - & - & - & 0 & + & 62 mo NED \\
\hline 18 & $57 / \mathrm{F}$ & Nucha & 15 & - & ++ & - & - & 4 & + & 172 mo NED \\
\hline 19 & $26 / \mathrm{F}$ & Retroperitoneum & 7 & + & - & + & + & 5 & - & 8 mo NED \\
\hline 20 & $61 / \mathrm{M}$ & Retroperitoneum & 11 & ++ & - & ++ & + & 17 & + & 4 mo NED \\
\hline
\end{tabular}

MC, myxoid change; SP, storiform pattern; NC, necrosis; HM, hemorrhage; HPF, high power field; P, pleomorphism; NA, not available; NED, no evidence of disease; mo, months.

extrapleural SFTs and between ordinary and malignant SFTs was evaluated by two-sided $\chi^{2}$ tests with Yates continuity correction. The difference in MIB-1 LI was estimated by the unpooled two-sample t-test. A P-value $<0.05$ was considered significant.

\section{Results}

Clinical findings. The clinical features of 20 extrapleural and 16 pleural SFT patients are summarized in Tables I and II, respectively. Of the 20 extrapleural SFT patients, only 10 were female $(50 \%)$, whereas females were predominantly affected by pleural SFTs $(11 / 16 ; 69 \%)$. Patient age ranged from 5 to 76 years (average 50.7). The most common extrapleural sites were the retroperitoneum (4 cases), abdominal wall (3 cases) and pelvic cavity ( 3 cases), followed by 2 in the orbit, 2 in the thigh, and 1 each in the abdominal cavity, oral cavity, groin, deltoid region, buttock and nucha. As for pleural SFTs, 4/16 tumors $(25 \%)$ were attached to visceral pleura, compressing the underlying lung. Follow-up data were available in 23 patients with a duration ranging from 2 to 197 months (mean 54). Consequently, only one case of pleural SFT recurred locally at 197 months after initial surgery (Case 14), and none of the tumors metastasized.
Pathological findings. Macroscopically, tumor size ranged from 1 to $27 \mathrm{~cm}$ in maximum diameter (mean 9.0), although the sizes of six tumors were not known. There were no significant differences in tumor size between pleural and extrapleural SFTs. The tumors were described as oval-to-round well-circumscribed or encapsulated masses with gray-to-tan fibrous cut surfaces (Fig. 1A). In this series, no tumors showed invasive growth to the surrounding tissue.

Microscopically, the tumors were composed of a proliferation of spindle or round cells arranged in patternless architecture, with prominent branching hemangiopericytoma-like vessels throughout the tumor (Fig. 1B). The cellularity of each tumor varied from area to area, depending on the degree of stromal collagenization, and in the less cellular areas the stroma was dense sclerotic and markedly hyalinized. The stroma often showed a lace-like network or keloid-like bundles of collagen separating individual tumor cells (Fig. 1C). These findings were commonly observed in both ordinary and malignant SFTs.

According to the histological definition of malignant SFTs, four cases of extrapleural and two cases of pleural malignant SFTs were identified (Tables I and II). Among extrapleural malignant SFTs, three cases showed frequent mitotic figures of $>4 / 10$ HPFs (Cases 18, 19 and 20; Fig. 1D), whereas three 
Table II. Clinical and pathologic data of 16 patients with pleural solitary fibrous tumor.

\begin{tabular}{|c|c|c|c|c|c|c|c|c|c|c|}
\hline $\begin{array}{l}\text { Case } \\
\text { no. }\end{array}$ & $\begin{array}{l}\text { Age (years)/ } \\
\text { gender }\end{array}$ & $\begin{array}{l}\text { Location } \\
\text { (pleura) }\end{array}$ & $\begin{array}{l}\text { Size } \\
(\mathrm{cm})\end{array}$ & $\mathrm{MC}$ & SP & $\mathrm{NC}$ & HM & $\begin{array}{l}\text { Mitosis/ } \\
10 \mathrm{HPF}\end{array}$ & $\mathrm{P}$ & Follow-up \\
\hline 1 & $57 / \mathrm{F}$ & Visceral & 10 & - & - & - & - & 0 & - & NA \\
\hline 2 & $53 / \mathrm{F}$ & Parietal & 5 & - & - & - & - & 0 & - & NA \\
\hline 3 & $45 / \mathrm{F}$ & Parietal & 14 & - & + & - & - & 0 & - & NA \\
\hline 4 & $5 / \mathrm{F}$ & Parietal & NA & + & - & - & - & 0 & - & NA \\
\hline 5 & $30 / \mathrm{M}$ & Parietal & 12 & - & + & - & - & 0 & - & 73 mo NED \\
\hline 6 & $50 / \mathrm{F}$ & Parietal & 12 & + & - & - & - & 0 & - & 66 mo NED \\
\hline 7 & $51 / \mathrm{M}$ & Visceral & NA & - & - & - & - & 0 & - & 64 mo NED \\
\hline 8 & $18 / \mathrm{F}$ & Parietal & 4 & + & - & - & + & 0 & - & 58 mo NED \\
\hline 9 & $44 / F$ & Parietal & 7 & - & + & - & - & 0 & - & 54 mo NED \\
\hline 10 & $45 / \mathrm{M}$ & Visceral & 6.5 & - & - & - & - & 0 & - & 30 mo NED \\
\hline 11 & $32 / \mathrm{M}$ & Visceral & NA & + & - & - & - & 0 & - & NA \\
\hline 12 & $62 / \mathrm{F}$ & Parietal & 12 & - & - & - & - & 0 & - & 148 mo NED \\
\hline 13 & $61 / \mathrm{F}$ & Parietal & 10 & - & - & - & - & 0 & - & NA \\
\hline 14 & $65 / \mathrm{F}$ & Parietal & 15 & - & + & - & - & 0 & - & 197 mo LR \\
\hline \multicolumn{11}{|c|}{ Malignant } \\
\hline 15 & $74 / \mathrm{F}$ & Parietal & 8 & - & - & - & - & 8 & - & 2 mo NED \\
\hline 16 & 76/M & Parietal & 10.9 & + & - & + & - & 10 & - & $\begin{array}{l}9 \text { mo succumbed } \\
\text { to other causes }\end{array}$ \\
\hline
\end{tabular}

MC, myxoid change; SP, storiform pattern; NC, necrosis; HM, hemorrhage; HPF, high power field; P, pleomorphism; NA, not available; NED, no evidence of disease; LR, local recurrence; mo, months.

cases disclosed prominent nuclear pleomorphism (Cases 17, 18 and 20; Fig. 1E). Nuclear pleomorphism was focally observed in two cases (Cases 17 and 18), while the remaining case exhibited diffuse nuclear pleomorphism. As for the pleural malignant SFTs, the two tumors revealed mitoses of $>4 / 10$ HPFs (Cases 15 and 16). One tumor showed marked cellular proliferation of spindle cells with frequent mitotic figures (Case 16; Fig. 1F). No difference was found in tumor size between ordinary and malignant or between extrapleural and pleural tumors.

Six of 20 cases (30\%) of extrapleural SFTs (Fig. 2A) and $5 / 16$ cases $(31 \%)$ of pleural SFTs exhibited myxoid change in $<50 \%$ of the tumor tissue. Seven cases of extrapleural SFTs (35\%, Fig. 2B) and four cases of pleural SFTs (25\%) revealed a storiform pattern. Stromal hemorrhage was observed in three cases $(15 \%)$ of extrapleural SFTs and one case $(6 \%)$ of pleural SFT. As for the presence of myxoid change, storiform pattern and stromal hemorrhage, there was no significant difference between extrapleural and pleural or between ordinary and malignant SFTs. Tumor necrosis was present in two cases (10\%, Fig. 2C) of extrapleural SFTs and one case $(6 \%)$ of pleural tumor. These three cases exhibited malignant SFTs. The existence of tumor necrosis was significantly frequent in malignant SFTs $(\mathrm{P}=0.0012)$.

Immunohistochemical findings. Immunohistochemical results are summarized in Table III. In 34/36 cases, tumor cells showed positive immunoreactivity for CD34, at least focally
(Fig. 3A). In all of the tumors, positive staining for bcl-2 protein was observed, at least focally (Fig. 3B). Three cases of extrapleural tumors and one pleural tumor revealed focal immunoreactivity for $\alpha$-smooth muscle actin. No cases showed a positive reaction for cytokeratin. p53 expression was focally (0-25\% of tumor cells) observed in five extrapleural tumors $(25 \%)$ and one pleural tumor $(6 \%)$. Four out of 6 malignant SFTs $(67 \%)$ showed p53 nuclear accumulation (Fig. 3C), whereas only $2 / 30(6 \%)$ ordinary SFTs revealed immunoreactivity for p53. p53 expression was significantly frequent in malignant SFTs $(\mathrm{P}=0.0027)$, although immunoreactive cells were focally seen. The MIB-1 LI ranged from 3.0 to 19.7 (mean 8.306). No statistical difference was observed in the MIB-1 LI between extrapleural and pleural SFTs (Table IV), while it was significantly higher in malignant (mean 13.48) (Fig. 3D) than in ordinary (mean 7.27) SFTs (Fig. 3E) (Table IV, $\mathrm{P}=0.0023$ ).

\section{Discussion}

A solitary fibrous tumor (SFT) was first described in 1931 in a patient with a distinctive pleural lesion (10). This tumor also arises in extra-pleural sites such as the deep soft tissue of the extremities, the head and neck (especially the orbit), the peritoneum and the retroperitoneum $(4,5,7,11,12)$. Previously, most cases of extrapleural SFTs were termed hemangiopericytoma $(2,13)$. However, the entity of extrapleural SFTs has been established as a mesenchymal tumor with a prominent 

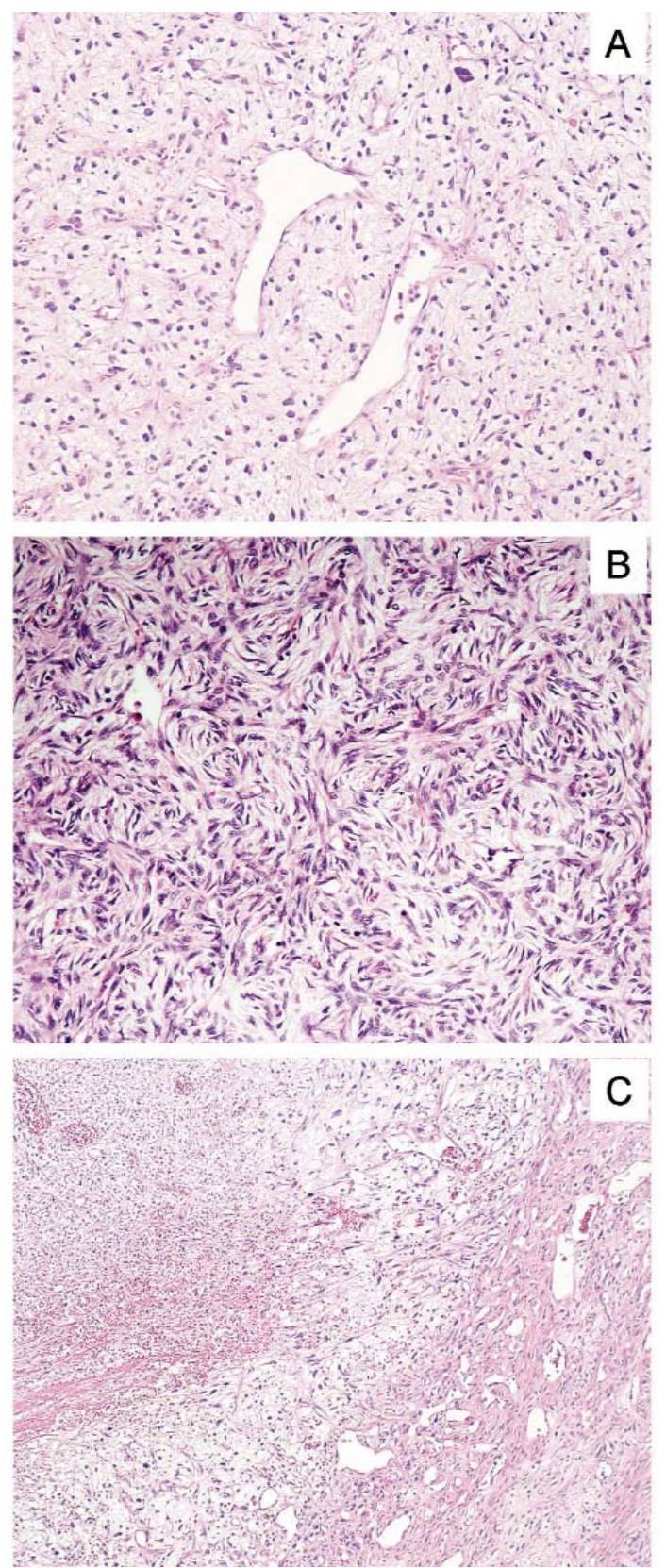

Figure 2. (A) Partially, the tumor shows myxoid stroma with abundant vessels and scattered pleomorphic cells, mimicking the features of myxofibrosarcoma (malignant extrapleural SFT; Case 20). (B) Storiform pattern is evident (malignant extrapleural SFT; Case 18). (C) Tumor necrosis with stromal hemorrhage is prominent (malignant extrapleural SFT; Case 20).

hemangiopericytoma-like branching vascular pattern, although it does share a morphological spectrum with hemangiopericytoma, lipomatous hemangiopericytoma and giant cell angiofibroma $(2,14-16)$. In this study, we retrieved 20 cases of extrapleural SFTs according to the most recent definition of the tumor $(2,16)$.

The histological criteria for the malignant variant of pleural SFTs were first proposed by England et al (3). They determined a tumor to be malignant if it exhibited at least one of the following characteristics: high cellularity, high mitotic activity, or pleomorphism. These three histological findings are considered to define the malignant variant in extrapleural $(5,11)$ and pleural $(8,17)$ SFTs, although some authors regard necrosis alone as defining the malignant phenotype in extrapleural
Table III. Immunohistochemical results in extrapleural and pleural solitary fibrous tumor.

\begin{tabular}{|c|c|c|c|c|c|c|}
\hline \multicolumn{7}{|c|}{ Extrapleural solitary fibrous tumor } \\
\hline Case no. & CD34 & bcl-2 & $\alpha-S M A$ & CK & p53 & MIB-1 LI \\
\hline 1 & +++ & +++ & - & - & - & 15.2 \\
\hline 2 & +++ & ++ & - & - & - & 6.5 \\
\hline 3 & +++ & ++ & - & - & - & 4.5 \\
\hline 4 & +++ & + & - & - & + & 7.7 \\
\hline 5 & +++ & +++ & - & - & - & 3.4 \\
\hline 6 & +++ & ++ & - & - & - & 4.0 \\
\hline 7 & - & ++ & - & - & - & 7.7 \\
\hline 8 & +++ & ++ & - & - & - & 13.0 \\
\hline 9 & +++ & + & - & - & - & 9.6 \\
\hline 10 & + & ++ & - & - & - & 8.8 \\
\hline 11 & +++ & + & - & - & - & 12.8 \\
\hline 12 & +++ & ++ & + & - & - & 8.0 \\
\hline 13 & + & +++ & + & - & - & 6.5 \\
\hline 14 & +++ & +++ & + & - & - & 4.4 \\
\hline 15 & +++ & ++ & - & - & - & 3.4 \\
\hline 16 & +++ & + & - & - & - & 4.9 \\
\hline \multicolumn{7}{|c|}{ Malignant } \\
\hline 17 & +++ & + & - & - & + & 8.1 \\
\hline 18 & +++ & ++ & - & - & + & 15.0 \\
\hline 19 & + & + & - & - & + & 19.7 \\
\hline 20 & + & + & - & - & + & 19.0 \\
\hline
\end{tabular}

Pleural solitary fibrous tumor

Case no. $\quad$ CD34 bcl-2 $\quad \alpha$-SMA $\quad$ CK $\quad$ p53 MIB-1 LI

\begin{tabular}{lcccccc}
\hline 1 & +++ & +++ & - & - & - & 4.4 \\
2 & +++ & + & - & - & - & 3.8 \\
3 & - & ++ & - & - & - & 4.0 \\
4 & +++ & + & - & - & - & 18.0 \\
5 & +++ & ++ & - & - & - & 4.9 \\
6 & +++ & ++ & - & - & - & 4.0 \\
7 & +++ & + & - & - & - & 4.5 \\
8 & +++ & + & - & - & + & 4.2 \\
9 & +++ & +++ & + & - & - & 12.6 \\
10 & +++ & + & - & - & - & 9.5 \\
11 & +++ & ++ & - & - & - & 3.0 \\
12 & +++ & ++ & - & - & - & 3.7 \\
13 & +++ & + & - & - & - & 8.8 \\
14 & ++ & ++ & - & - & - & 12.3 \\
& & & & & & \\
Malignant & & & & & & \\
15 & ++ & + & - & - & - & 8.6 \\
16 & +++ & +++ & - & - & - & 10.5 \\
\hline
\end{tabular}

tumors (7). Gold et al analyzed 79 cases of extrapleural and pleural SFTs (18), and defined the malignant component as the areas showing at least one of the above three histological findings, not including necrosis. In their large series, a malignant 

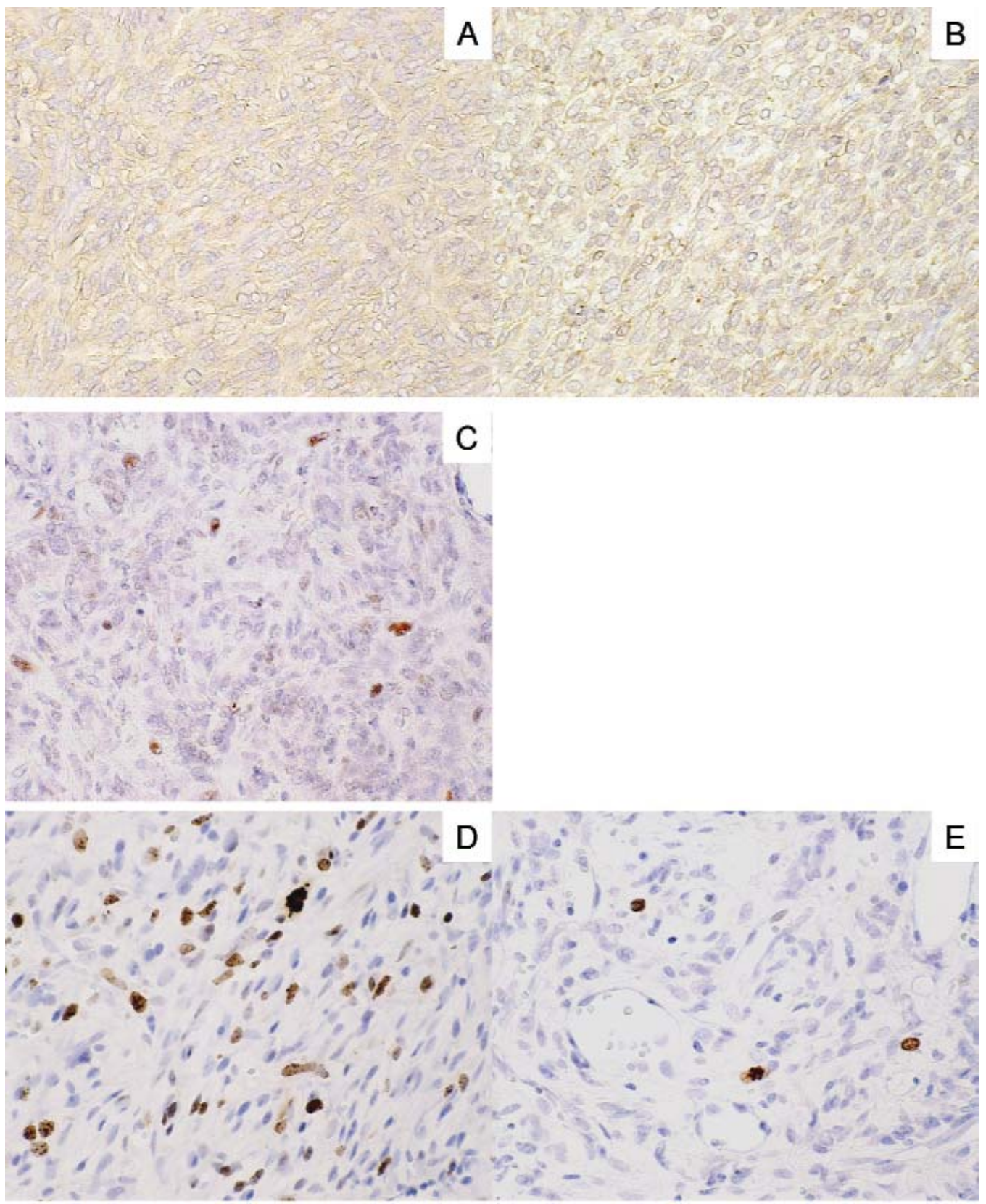

Figure 3. (A and B) Immunohistochemically, oval tumor cells are positive for CD34 (A) and bcl-2 (B) in their cytoplasm (malignant pleural SFT; Case 16). (C) p53 immunoreactive cells scattered throughout the tumor (malignant extrapleural SFT; Case 17). (D and E) The MIB-1 LI of malignant extrapleural SFTs. (D) (MIB-1 LI 19.0; Case 20) is higher than that of ordinary extrapleural SFTs and (E) (MIB-1 LI 4.5; Case 3).

Table IV. Comparison of MIB-1 LI between extrapleural and pleural SFTs, and between ordinary and malignant SFTs.

MIB-1-LI

\begin{tabular}{lccc}
\cline { 2 - 4 } SFT & Average & SD & P-value \\
\hline Extrapleural $(\mathrm{n}=20)$ & 9.11 & 5.04 & 0.2638 \\
Pleural $(\mathrm{n}=16)$ & 7.30 & 4.34 & \\
Ordinary $(\mathrm{n}=30)$ & 7.27 & 4.03 & $0.0023^{\mathrm{a}}$ \\
Malignant $(\mathrm{n}=6)$ & 13.48 & 5.16 & \\
\hline
\end{tabular}

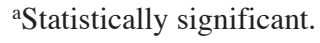

component was observed in $20 \%$ of cases; the presence of such a component was correlated with higher rates of local recurrence and with worse chances of metastasis-free survival. They also evaluated the predictive value of necrosis alone, but failed to find any predictive value of metastasis in tumor necrosis. However, as necrosis was more frequently observed in the malignant variant in the current study, it may also be a histological parameter of the malignant phenotype in SFTs.

In our series, malignant histology was identified in 6 out of 36 cases $(17 \%)$. However, the presence of malignant histology in extrapleural and pleural tumors did not affect the clinical outcome of the patients. Several authors demonstrated that, in extrapleural and pleural tumors, some histologically malignantlooking lesions behave benignly, whereas some morphologically innocuous lesions occasionally behave aggressively 
$(3,5,19,20)$. Therefore, the biological behavior of the current series may be consistent with previous reports.

As for extrapleural SFTs, no metastasizing cases have been documented in any relatively large series containing the histologically malignant variant (4-6), whereas one series reported 5 metastasizing cases among their 10 cases of atypical/ malignant extrapleural SFTs (7). We were also unable to find any metastasizing cases of extrapleural SFTs, even in the histologically malignant phenotype. Our results and those of previous investigations suggest that most extrapleural SFTs behave in a benign fashion even in the malignant histology group, and that it is difficult to predict their clinical outcome by histopathological morphology alone.

Although focal myxoid change is a relatively wellrecognized feature of SFTs, Somerhausen et al (21) reported seven cases of SFTs with extensive myxoid areas of $>50 \%$ and diagnosed them as myxoid SFTs. This phenotype may be misdiagnosed as low-grade fibromyxoid sarcoma, myxoid synovial sarcoma, malignant peripheral nerve sheath tumor, or low-grade myxofibrosarcoma. In our study, a myxoid change of $<50 \%$ of the tumor was recognized in 11 out of 36 cases. There were no differences in the frequency of myxoid change between extrapleural and pleural SFTs or between ordinary and malignant SFTs.

Positive immunoreactivities of tumor cells for CD34 have been reported to be characteristic of pleural and extrapleural SFTs $(1,2)$. However, some investigators have demonstrated a loss of CD34 expression in atypical/malignant (7) or cellular (16) extrapleural SFTs, and in high-grade (17) or aggressive (22) pleural SFTs. In this study, the loss of CD34 expression was observed in only two cases of ordinary SFTs (one extrapleural and one pleural), and was not correlated with their biological behavior. SFTs have also been reported to show frequent immunoreaction to bcl-2 (5). In this study, the extrapleural and pleural SFT cases reacted positively to bcl-2, at least focally.

Concerning proliferative activity and molecular alterations, Brozzetti et al (22) demonstrated that high Ki-67 expression was correlated with malignant histology and poor prognosis in pleural SFTs. Moreover, high telomerase activity and a high LI in Ki-67, cyclin D1 and cyclin A have also been linked to malignant histology in pleural SFTs (9). However, Morimitsu et al (6) reported that the p53, MDM2 and Ki-67 LIs were generally low in extrapleural SFTs, and detected only one case with a p53 point mutation. In this study, a high MIB-1 (Ki-67) LI and p53 expression were significantly correlated with malignant histology, although immunoreactive cells for p53 were seen focally.

In conclusion, further investigation with the aim of uncovering a novel biomarker of SFTs would be useful, as it is very difficult to reliably predict the behavior of extrapleural or pleural lesions by analyzing the currently known histological findings or molecules.

\section{Acknowledgements}

This work was supported by a Grant-in-Aid for Scientific Research (C) from the Japan Society for the Promotion of Science (18590332), Tokyo, Japan. The English used in this manuscript was revised by KN International (http://www. kninter.com/).

\section{References}

1. Travis, WD, Tazelaar H, Churg A, et al: Solitary fibrous tumour (SFT). In: World Health Organization Classification of Tumours. Pathology and Genetics of Tumours of the Lung, Pleura, Thymus, and Heart. Travis WD, Brambilla E, Muller-Hermelink HK and Harris CC (eds). IARC Press, Lyon, pp142-143, 2004.

2. Guillou L, Fletcher JA, Fletcher CDM and Mandahl N: Extrapleural solitary fibrous tumour and haemoagniopericytoma. In: World Health Organization Classification of Tumours. Pathology and Genetics of Tumours of Soft Tissue and Bone. Fletcher CDM, Unni KK and Mertens F (eds). IARC Press, Lyon, pp86-90, 2002.

3. England DM, Hochholzer L and McCarthy MJ: Localized benign and malignant fibrous tumors of the pleura. A clinico-pathologic review of 223 cases. Am J Surg Pathol 13: 640-658, 1989.

4. Brunnemann RB, Ro JY, Ordnez NG, Mooney J, El-Nagger AK and Ayala AG: Extrapleural solitary fibrous tumor: A clinicopathologic study of 24 cases. Mod Pathol 12: 1034-1042, 1999.

5. Hasegawa T, Matsuno Y, Shimoda T, Hasegawa F, Sano T and Hirohashi S: Extrathoracic solitary fibrous tumors: Their histological variability and potentially aggressive behavior. Hum Pathol 30: 1464-1473, 1999.

6. Morimitsu Y, Nakajima M, Hisaoka M and Hashimoto H: Extrapleural solitary fibrous tumor: Clinicopathologic study of 17 cases and molecular analysis of the p53 pathway. APMIS 108: 617-625, 2000.

7. Vallat-Decouvelaere AV, Dry SM and Fletcher CDM: Atypical and malignant solitary fibrous tumors in extrathoracic locations. Evidence of their comparability to intra-thracic tumors. Am J Surg Pathol 22: 1501-1511, 1998.

8. Hanau CA and Miettinen M: Solitary fibrous tumor: Histological and immunohistochemical spectrum of benign and malignant variants presenting at different sites. Hum Pathol 26: 440-449, 1995.

9. Miracco C, de Santi MM, Pacenti L, et al: Teromerase activity, Ki-67, cyclin D1 and A expression, and apoptosis in solitary fibrous tumors: additional features of a predictable course? Pathol Res Pract 197: 475-481, 2001.

10. Klemperer P and Rabin CP: Primary neoplasm of the pleura: A report of five cases. Arch Pathol 11: 385-412, 1931.

11. Fukunaga M, Naganuma $H$, Ushigome $S$, Endo $Y$ and Ishikawa $E$ : Malignant solitary fibrous tumor of the peritoneum. Histopathology 28: 463-466, 1996.

12. Hasegawa T, Hirose T, Seki K, Yang P and Sano T: Solitary fibrous tumor of the soft tissue. An immunohistochemical and ultrastructural study. Am J Clin Pathol 106: 325-331, 1996.

13. Espat NJ, Lewis JJ, Leung D, Woodruff JM, Antonescu CR, Shia J and Brennan MF: Conventional hemangiopericytoma. Modern analysis of outcome. Cancer 95: 1746-1751, 2002.

14. Dei Tos AP, Seregard S, Calonje E, Chan JK and Fletcher DM: Giant cell angiofibroma. A distinctive orbital tumour in adults. Am J Surg Pathol 19: 1286-1293, 1995.

15. Guillou L, Gebhard S and Coindre JM: Lipomatous hemangiopericytoma: A fat-containing variant of solitary fibrous tumor? Clinicopathologic, immunohistochemical, and ultrastructural analysis of a series in favor of a unifying concept. Hum Pathol 31: 1108-1115, 2000.

16. Gengler C and Guillou L: Solitary fibrous tumour and haemangiopericytoma: Evolution of a concept. Histopathology 48: 63-74, 2006.

17. Yokoi T, Tsuzuki T, Yatabe Y, et al: Solitary fibrous tumour: Significance of p53 and CD34 immunoreactivity in its malignant transformation. Histopathology 32: 423-432, 1998.

18. Gold JS, Antonescu CR, Hajdu C, et al: Clinicopathologic correlates of solitary fibrous tumors. Cancer 94: 1057-1068, 2002.

19. Witkin GB and Rosai J: Solitary fibrous tumor of the mediastinum. A report of 14 cases. Am J Surg Pathol 13: 547-557, 1989.

20. Moran CA, Suster S and Koss MN: The spectrum of histologic patterns in benign and malignant fibrous tumors of the pleura. Sem Diag Pathol 9: 169-180, 1992.

21. Somerhausen NDSA, Rubin BP and Fletcher CDM: Myxoid solitary fibrous tumor: A study of seven cases with emphasis on differential diagnosis. Mod Pathol 12: 463-471, 1999.

22. Brozzetti S, D'Andrea N, Limiti MR, Pisanelli MC, De Angelis R and Cavallaro A: Clinical behavior of solitary fibrous tumors of the pleura. An immunohistochemical study. Anticancer Res 20: 4701-4706, 2000. 